\title{
GRAIN-SIZE SORTING IN THE SWASH ZONE ON UNEQUILIBRIUM BEACHES AT THE TIMESCALE OF INDIVIDUAL WAVES
}

\author{
Tetauya Kakinoki ${ }^{1}$, Gozo Tsujimoto ${ }^{1}$ and Kohji Uno ${ }^{1}$
}

\begin{abstract}
The purpose of this study is to investigate sediment grain size and morphological change in the swash zone using Image processing technique and wave gages. Although a number of researches have been carried out into sediment transport and morphological change in the swash zone, quantity of sand transport and topography in that area has not been measured directly. It was found that the technique of this study could measure the sediment grain size and bed elevations in the swash zone.
\end{abstract}

Keywords: grain-size sorting; swash zone; morphological change; image processing

\section{INTRODUCTION}

The sorting of sediments along a beach profile produces cross-shore variations in sediment grain sizes. The largest sediment particles generally are located in the high energy area, such as breaker and berm-crest zones, with a decrease in grain sizes both toward deeper water and shoreward across the surf and swash zone (Komar 1998; Briggs 1977). An interesting variation occurs in the transition zone between the surf and swash zones where erosion removes finer material, leaving coarse lag deposit. It illustrates the fact that coarse-grained sediment can result from the loss of fine material from mixed sediment as well as the introduction of coarse material (Briggs 1977).

In comparison with hydrodynamics of the swash motion, measurements of sediment load using conventional method can be highly problematic, due to the difficulties, particularly wets and dries, very small water depths, aerated and high velocity. For this reason, it is not clear that the sediment transport for each size of particle and sediment sorting in the swash zone. The purpose of this study is to investigate process of grain-size sorting in the swash zone at the time scale of individual waves in laboratory.

\section{EXPERRIMENTAL CONDITIONS}

Experiments were performed in a two dimensional wave flume $18.0 \mathrm{~m}$ long, $0.6 \mathrm{~m}$ wide and $0.8 \mathrm{~m}$ high, with working water depth of $0.35 \mathrm{~m}, 0.38 \mathrm{~m}$ on a $1 / 10$ sand slope (figure 1). Median diameter $\mathrm{D}_{50}$ $=0.46 \mathrm{~mm}$, sorting coefficient $\mathrm{S}_{0}=1.31$. Vertical elevations of free surface wave and bottom surface were recorded using capacitance-type gauges distributed along the wave flume. Table $\mathbf{1}$ shows wave conditions. For these tests water depth was varied to simulate a sea level change $(\mathrm{h}=35 \mathrm{~cm} \rightarrow 38 \mathrm{~cm} \rightarrow$ $35 \mathrm{~cm}$ ). Grain-size distributions of bed material were observed with image analysis (Rubin 2004) under the conditions.

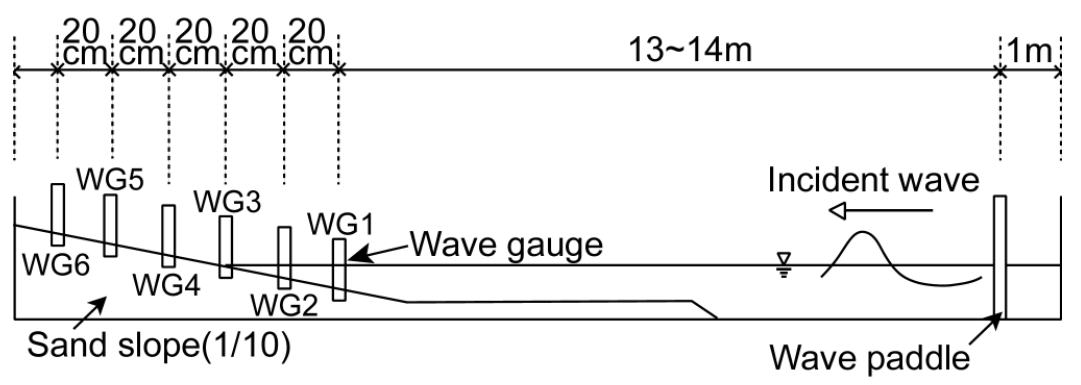

Figure 1 Two dimensional wave flume.

\footnotetext{
${ }^{1}$ Civil Eng., Kobe City College of Technology, 8-3 Gakuen-higashi, Nishi ward, Kobe, Hyogo, 651-2194, Japan
} 


\begin{tabular}{|c|c|c|c|}
\hline \multicolumn{4}{|l|}{ Table 1. Wave conditions. } \\
\hline Test & A1 & A2 & A3 \\
\hline Wave type & \multicolumn{3}{|c|}{ Monochromatic wave } \\
Wave making length & $50 \mathrm{~min}$ & $45 \mathrm{~min}$ & $45 \mathrm{~min}$ \\
Water depth $(\mathrm{cm})$ & 35.0 & 38.0 & 35.0 \\
Wave period $(\mathrm{sec})$ & 2.0 & 2.0 & 2.0 \\
Wave height $(\mathrm{cm})$ & 10.0 & 10.0 & 10.0 \\
\hline
\end{tabular}

\section{MEASUREING OF BOTTOM ELEVATION}

Sediment transport rate of each size is required to clarify the mechanism of grain-size sorting swash-by-swash. The present work is an attempt to observe bed levels and diameter distributions at the time scale of individual waves for sediment transport rate derived from conservation law of sand. Sediment transport rate in the swash zone cannot be measured by using conventional method, since the water depth is very shallow and the bottom surface is alternately covered and exposed. For this reason, a sensor of capacitance-type wave gauge was implanted into the beach for measuring swash depth and bed levels. Furthermore, image of the bottom surface in the swash zone was taken from above after backwash passed, and grain-size distributions swash by swash was obtained by image processing.

Dielectric constant of sand is sufficiently larger than that of water, if a bottom of swash zone is saturated when beach surface is exposed, the wave gauge can measure bottom elevations according to the principle of capacitance-type wave gauge. There would be no particular problem of this method because of wave period used in experiment were few seconds at the most. Figure 2 shows a schematic diagram of performance test of capacitance-type wave gauge which sensor was implanted into the bottom. Sand and water were put in an acrylic cylinder, and the sensor of capacitance-type wave gauge was implanted into the sediment for measuring water level.

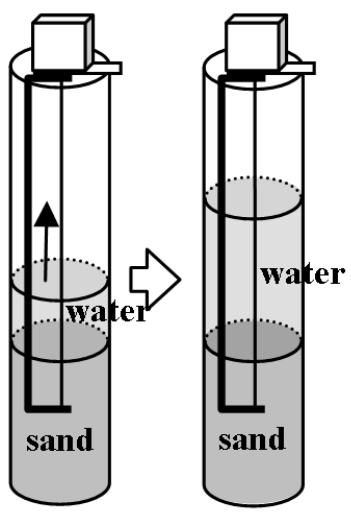

Test 1

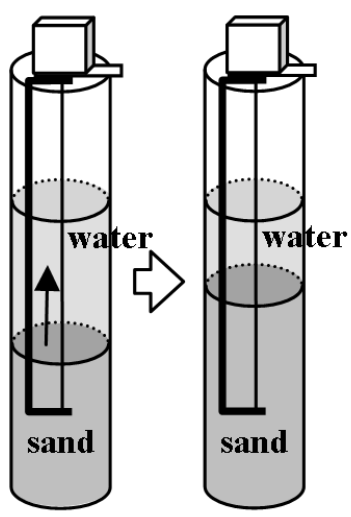

Test 2

Figure 2. Performance test of capacitance-type wave gauge that sensor was implanted into the bottom.

The results of performance test of wave gauge were shown in figure $\mathbf{3}$. Water level was varied and bed level was kept constant in Test1, conversely, in Test2 bed level was varied and water level was fixed. Horizontal axis shows water level, vertical axis shows output voltage from the wave gauge. In Test1, output voltage is proportional to water level when height of sand surface was kept constant all the time. While in the case of Test 2 when water level was fixed, output voltage was not affected by bed level change. Water level can be detected by capacitance-type wave gauge independently of existence of sand. It was verified that saturated beach face elevation in the swash zone was measurable by a capacitance-type wave gauge. Figure $\mathbf{4}$ shows an example of water and bed elevations obtained from the experiment. 


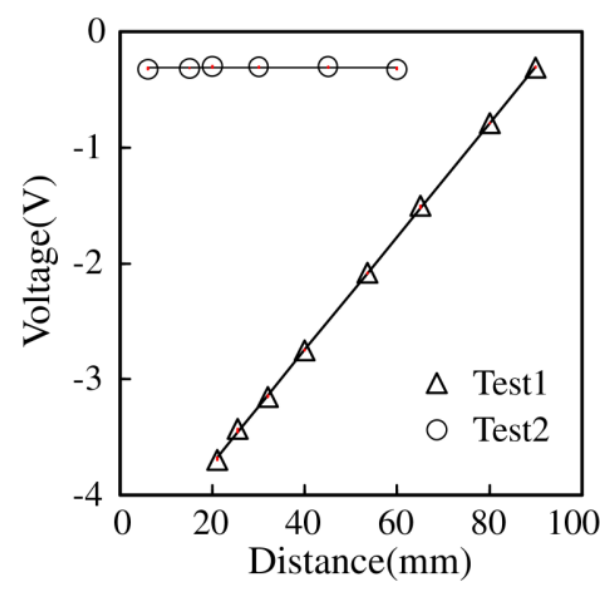

Figure 3. Results of the performance test of wave gauge.

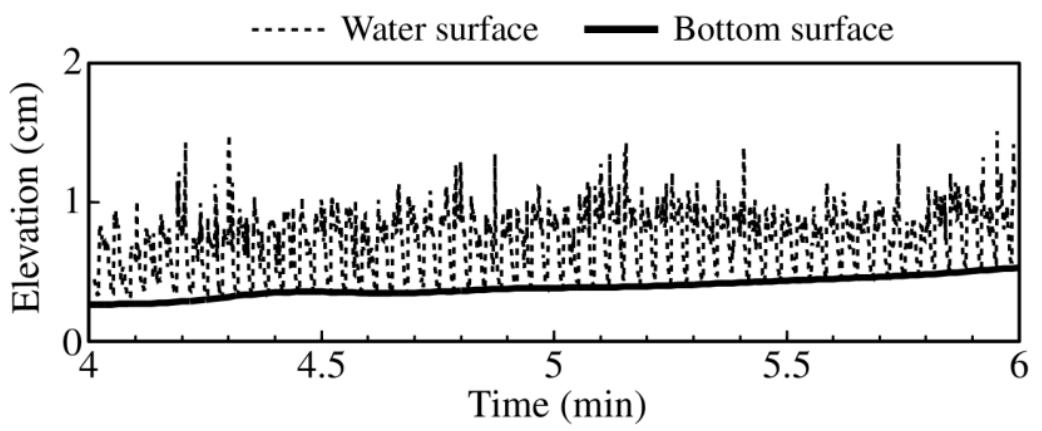

Figure 4. An example of water and bed elevations obtained from the experiment with wave gauge.

\section{GRAIN SIZE ANALYSIS BY IMAGE PROCESSING}

Core of sediment is pulled out after water is drained from wave flume by the method which has been used, and grain size was analyzed. Clarify of sorting process in the swash zone required both grain size of fluidized bed on beach surface and that of inside the bottom. Pictures of exposed beach face were taken by digital camera from above after backwash passed, and time series of grain size is obtained with image processing of Rubin's method (figure 5). Resolution of image was $0.01 \mathrm{~mm}$ per pixel.

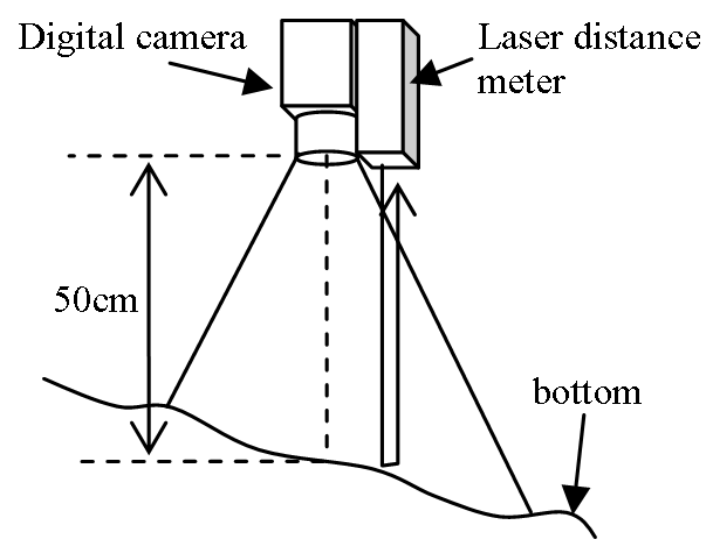

Figure 5. Camera station. 


\section{RESULTS}

\section{Morphological change}

Figure 6 shows experimental results of beach morphology. Dashed line is initial profile, solid line final profile, and alternate long and short dash line still water level. For these tests, water depth was varied to simulate sea level change. Beach morphology before and after was found by measurement by a laser range finder at a pitch of $2 \mathrm{~cm}$. Initial profile for a test was the end of profile of the previous test. Typical accretive profiles were formed in all the cases. Sediment was eroded from the lower part of a still water level and was deposited on the upper part.

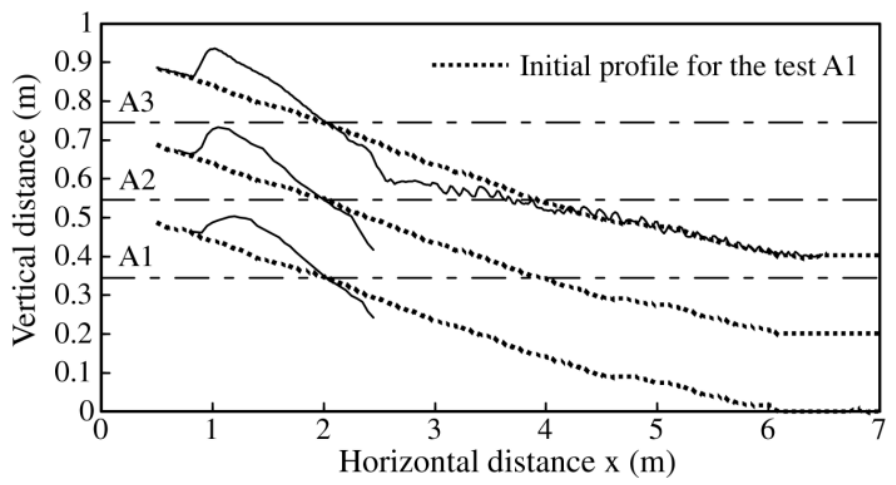

Figure 6. Beach morphology.

\section{Bottom elevation}

Figure 7 figure 9 show cumulative morphological change during a test at each point. Significant morphological change occurred during test A1. Vertical axis shows amount of morphological change. The berm height reached a peak in 23 25 minutes and leveled off in 30 minutes. The bottom height at the shore line of still water level remained stable. In figure $\mathbf{8}$, because the sea level rose by $3 \mathrm{~cm}$ from Test A1, the berm height increases slowly to the end. In figure 9, beach morphology remained stable and would reach an equilibrium beach profile.

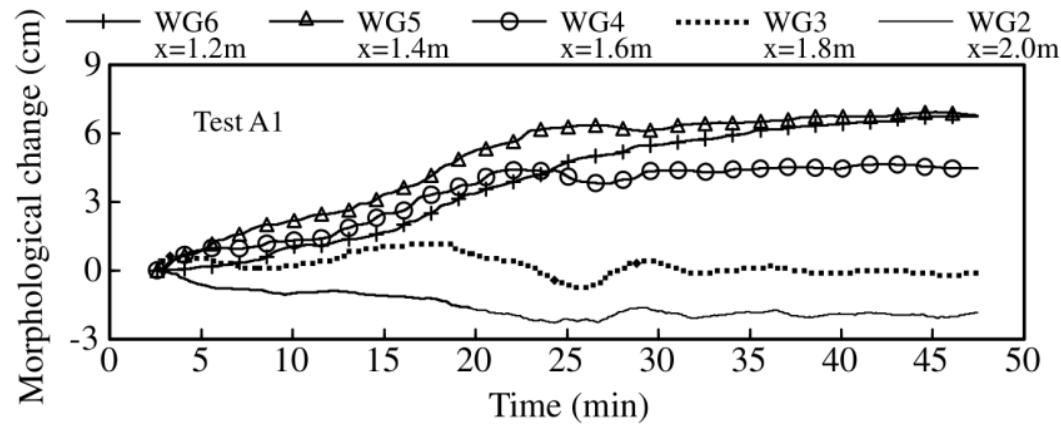

Figure 7. Cumulative morphological change of Test A1.

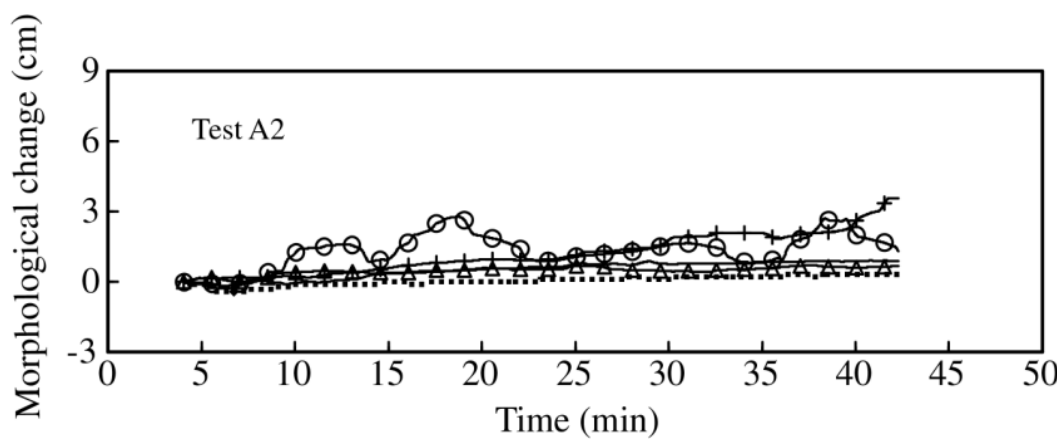

Figure 8. Cumulative morphological change of Test A2. 


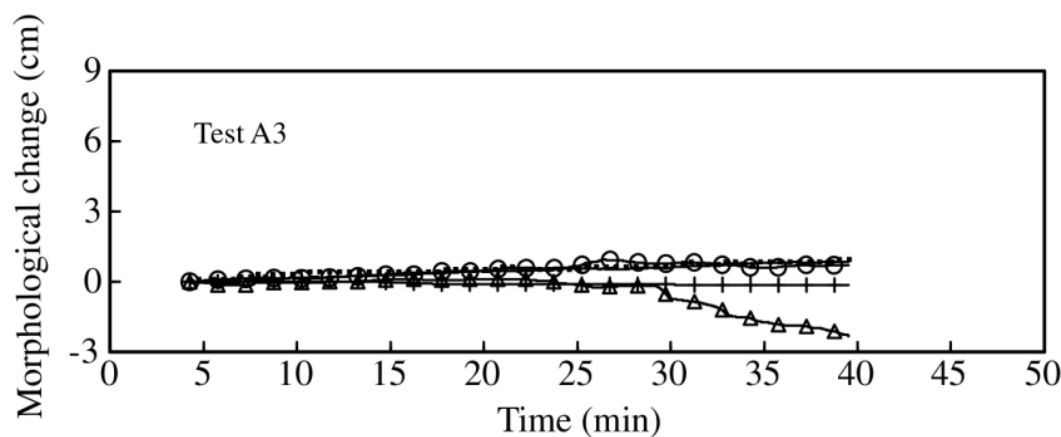

Figure 9. Cumulative morphological change of Test A3.

\section{Grain size and sediment transport rate}

Figure $10 \sim$ figure 12 show the result of TestA $1 \sim$ Test A3, the time series of grain size $\left(D_{50}\right)$ and sediment transport rate $q_{x}$ of the bottom surface. In this figure, horizontal axis shows horizontal distance in cross-shore direction, the left side vertical axis shows diameter of sand, the right side vertical axis shows sediment transport rate. The $q_{x}$ was calculated for each region by the data of morphological change and following equation,

$$
\frac{\partial h}{\partial t}=\frac{1}{1-\lambda} \frac{\partial q_{x}}{\partial x}
$$

where $h$ is local water depth, $t$ time, $\lambda$ porosity, $q_{x}$ sediment transport rate, $x$ horizontal axis. Positive $q_{x}$ values represent drift sand from offshore to onshore.

Figure 10 shows result of Test A1. In this figure, coarser particles mainly transported to the onshore direction in 12 minutes, and the value of $\mathrm{D}_{50}$ fell down $0.7 \mathrm{~mm}$ to $0.5 \mathrm{~mm}$ in $25 \sim 30$ minutes and leveled off in 30 minutes. Figure 11 shows the result of Test A2, the water level rose by $3 \mathrm{~cm}$ from Test A1. In this figure, sediment transport rate $q_{x}$ fluctuated between shoreward and seaward. Although coarser particles $\left(\mathrm{D}_{50}=0.8 \mathrm{~mm} \sim 0.9 \mathrm{~mm}\right)$ moved occasionally, the values of $\mathrm{D}_{50}$ remained constant during test $\mathrm{A} 2$. This explains that the coarser sand deposited around swash front or returned to the wave breaking point. Figure 12 shows the result of TestA3, the water level fell by $3 \mathrm{~cm}$ from Test A2. In this figure, beach morphology remained stable and reached an equilibrium beach profile, the sediment hardly transported, but the values of $D_{50}$ fluctuated. This explains that coarser sand on the surface only oscillate in the swash zone.

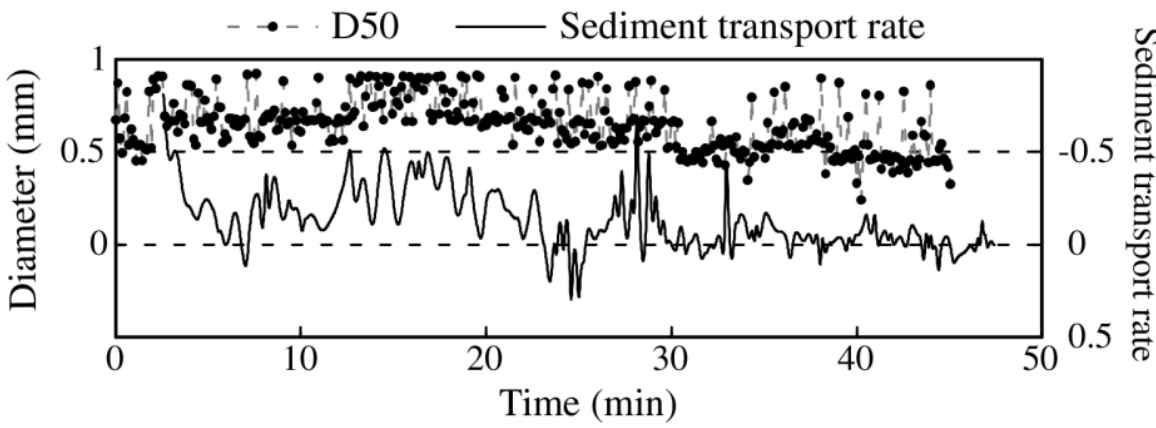

Figure 10. Time series of D50 and sediment transport rate. (Test A1) 


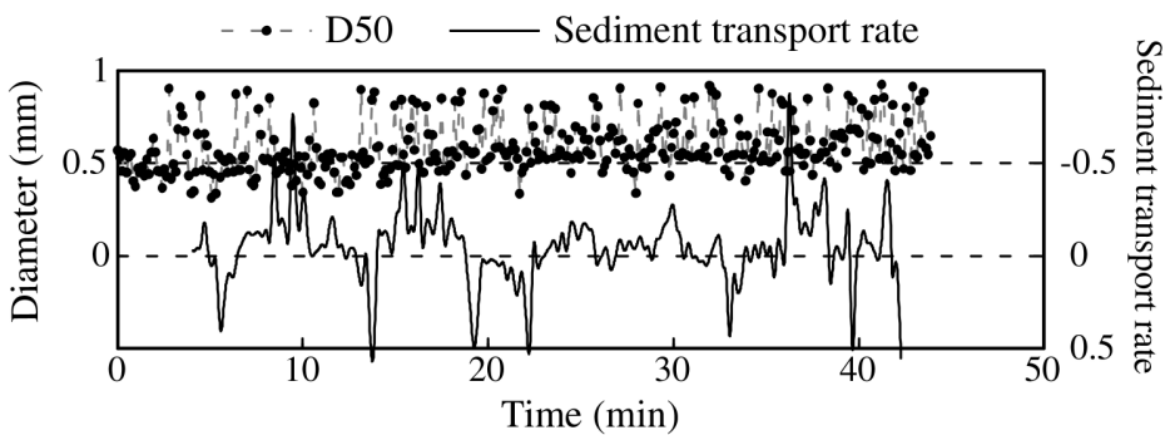

Figure 11. Time series of D50 and sediment transport rate. (Test A2)

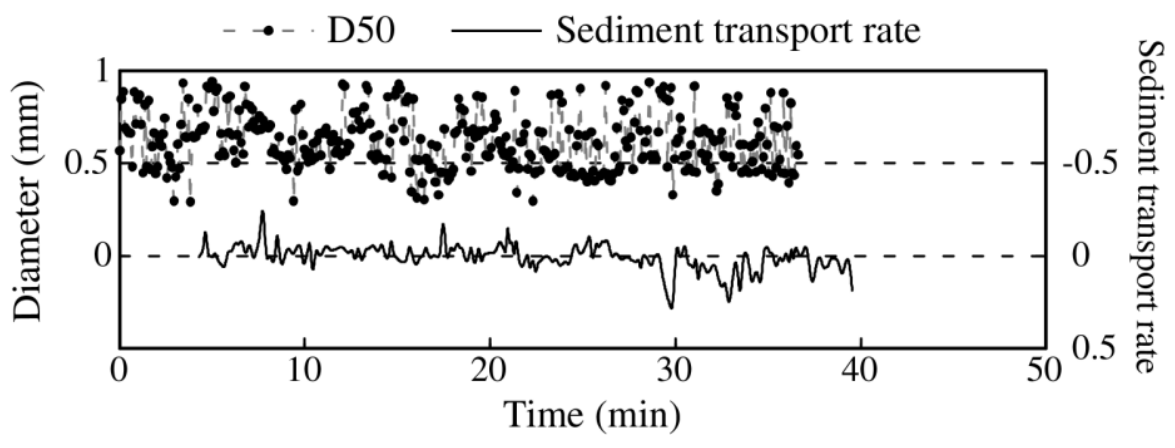

Figure 12. Time series of D50 and sediment transport rate. (Test A3)

\section{CONCLUSIONS}

In comparison with hydrodynamics of the swash motion, measurements of sediment load using conventional method can be highly problematic, due to the difficulties, particularly wets and dries, very small water depths, aerated and high velocity, in measurements. For this reason, it is not clear that the sediment transport for each size of particle and sediment sorting in the swash zone. The aim of this study is to investigate process of grain-size sorting in the swash zone at the time scale of individual waves in laboratory. The conclusions reached were as follows.

1. It was found that the technique of this study could measure the sediment grain size and bed elevations in the swash zone at the time scale of individual waves.

2. Sediment was transported selectively in grain size, coarser particles mainly transported to the onshore direction until beach profile reaches an equilibrium state.

3. Grain size of transporting sediment did not always agree with the size of bottom material in the swash zone.

\section{REFERENCES}

David, Briggs (1977): Particle size analysis, Sources and methods in geography: Sediments, Butterworth, 55-110.

D.M.Rubin (2004): A simple autocorrelation algorithm for determining grain size from digital images of sediment, Journal of Sedimentary Research, Vol.74, No.1, 160-165.

Paul D. Komar (1998): Beach morphology and sediments, Beach processes and sedimentation, Second Edition, Prentice Hall, 56-62. 